\title{
Circulatory effects and kinetics following acute administration of carbon monoxide in a porcine model
}

\author{
Anna-Maja Åberg*, Magnus Hultin, Pernilla Abrahamsson, Jan Erik Larsson \\ Department of Surgical and Perioperative Sciences, Division of Anesthesiology and Intensive Care, \\ Umea University Hospital, SE-901 85 Umea, Sweden
}

Received 30 May 2003; accepted 12 December 2003

\begin{abstract}
Carbon monoxide is produced in the endothelial cells and has possible vasodilator activity through three different pathways. The aim of this study was to demonstrate circulatory effects after administration of saturated carbon monoxide blood and to describe the pharmacokinetics of carbon monoxide. Six pigs were anesthetized and $150 \mathrm{ml}$ blood was removed. This blood was bubbled with carbon monoxide until the carboxyhemoglobin $(\mathrm{COHb})$ levels were $90-99 \%$. A specific amount of this blood was then injected back to the animal. At predetermined times; arterial and mixed venous blood was drawn and analyzed for carbon monoxide. Systemic and pulmonary vascular resistance index (SVRi and PVRi) were measured and exhaled air was sampled and measured for carbon monoxide. Blood samples were gathered over 300 minutes along with measurements of invasive pressures, heart rate, cardiac output, oxygen saturation $\left(\mathrm{SpO}_{2}\right), \mathrm{Hb}$, temperature and blood gases. We conclude that this type of exposure to carbon monoxide appears to have little or no effect on general vasomotor tone and, after correcting for basal levels of carbon monoxide, elimination occurs through the lungs as predicted by a single compartment model. The half-life of carbon monoxide was determined to be 60.5 minutes (SEM 4.7).
\end{abstract}

(C) 2004 Elsevier Inc. All rights reserved.

Keywords: Blood; Gas chromatography; Carbon monoxide; Pharmacokinetics; Half-life; Elimination; Pulmonary artery catheter; Pulmonary vascular resistance; Systemic vascular resistance; Circulation

\section{Introduction}

Carbon monoxide is produced in endothelial cells by degradation of heme by heme-oxygenase (HO). Studies in vitro have shown that carbon monoxide has vasodilatory effects through three possible

* Corresponding author. Tel.: +46-90-7851168; fax: +46-90-131388.

E-mail address: annamaja.aberg@anestesi.umu.se (A.-M. Åberg). 
mechanisms. Carbon monoxide diffuses from endothelial cells and into neighborly vascular smooth muscle cells where it binds to soluble guanylate cyclase, activating the enzyme and increases intracellular levels of cyclic GMP (cGMP) and relaxation of blood vessels. High-conductance calcium-activated $\mathrm{K}$ channels are also activated by carbon monoxide and cause vasodilatation. An indirect effect of carbon monoxide may be brought about by inhibition of the P-450 system, which may impair the formation of vasoconstrictor substances (Siow et al., 1999; Wang, 1998). Several studies have shown an increase in carbon monoxide, HO or mRNA for HO during various conditions including; resuscitation from hemorrhage (Bauer et al., 1996), hypertensive response (Motterlini et al., 1998), asthma (Horváth et al., 1998) and endotoxic shock (Yet et al., 1997). Heme oxygenase inhibition led to decreased cGMP (Durante et al., 1999; Motterlini et al., 1998) or increased portal resistance (Bauer et al., 1996; Pannen and Bauer, 1998; Suematsu et al., 1995). In perfused rat liver addition of carbon monoxide gave less vascular resistance (Suematsu et al., 1995).

Circulatory in vivo studies involving carbon monoxide are few. Endogenously produced carbon monoxide has not been shown to have effects on the circulation in vivo. Two studies (Grover et al., 2000; Vassalli et al., 2001) were not able to show any circulatory effects after inhalation of carbon monoxide, whereas one study (Nachar et al., 2001) showed a decrease in pulmonary vascular resistance after inhalation of carbon monoxide.

The pharmacokinetics of carbon monoxide has not been well described. Previous studies have described patients in whom carbon monoxide exposure was high (5-82\%), in fire victims (Weaver et al., 2000) or from inhalation of carbon monoxide (Kreck et al., 2001; Sasaki, 1975; Shimazu et al., 2000; Wazawa et al., 1996; Wagner et al., 1975). The aim of such studies was to investigate which factors influence the elimination of carbon monoxide and to find the best ventilation for the elimination. Elimination half-life varied significantly (5-190 minutes). Some investigators concluded that carbon monoxide elimination follows first orders kinetics (Kreck et al., 2001; Sasaki, 1975; Weaver et al., 2000) whereas others state it is of second order (Shimazu et al., 2000; Wagner et al., 1975). In one study it was concluded that carbon monoxide is eliminated according to third orders kinetics (Wazawa et al., 1996). Another conclusion in all of these studies was that the main factor determining rate of elimination of carbon monoxide from the body is the mode of ventilation.

In the present investigation, it was hypothesed that acute i.v. administration of carbon monoxide would induce circulatory effects due to its vasodilatory action. We aimed to expose a healthy anesthetized animal to a known amount of carbon monoxide, observe the circulatory effects and measure the distribution and elimination.

\section{Methods}

This study was performed using 6 female pigs weighing 24-30 kg. The study was approved by the University Animal Experimental Committee and performed in accordance with the NIH Institutional animal care and use committee guidebook 2002.

\section{Anesthesia}

For premedicination a mixture of ketamin $10 \mathrm{mg} \cdot \mathrm{kg}^{-1}$ (Ketalar ${ }^{\circledR}$, Parke-Davis, USA), azaperone 4 $\mathrm{mg} \cdot \mathrm{kg}^{-1}$ (Stresnil ${ }^{\circledR}$, Janssen-Cilag, Belgium) and atropine sulfate $0,05 \mathrm{mg} \cdot \mathrm{kg}^{-1}$ (Atropin, Kabi 
Pharmacia, Sweden) was given i.m. The pigs was also given a bolus of $300 \mathrm{mg}$ sodium pentobarbital (Pentobarbitalnatrium, Apoteksbolaget, Sweden) i.v. Infusion of $10-30 \mathrm{mg} \cdot \mathrm{kg}^{-1} \cdot \mathrm{h}^{-1}$ sodium pentobarbital was used during the whole experiment for maintenance of anesthesia. The animals were tracheotomised and mechanically ventilated with air containing 30\% oxygen, using a volume-cycled ventilator (Siemens 900B, Siemens-Elema, Germany). The ventilation was adjusted to obtain normoventilation from arterial blood gas analysis (ABL 5 autoanalyzer, Radiometer, Denmark). One liter Ringer's acetate was given to the animals immediately after the preparation, and this was followed by an infusion rate of $15 \mathrm{mg} \cdot \mathrm{kg}^{-1} \cdot \mathrm{h}^{-1}$. The body temperature was held at $37-39^{\circ} \mathrm{C}$, by covering the animal with blankets, as necessary.

\section{Instrumentation}

Three intravascular catheters where inserted in external jugular veins and in a branch of the external carotid artery. The arterial catheter tip was positioned in the descending aorta. The central vein catheter tip was placed in the superior vena cava, at the entrance to the right atrium. A 7F, four lumen, pulmonary artery catheter (PA) (Optimetrix, Abbot Inc. USA) was placed to an occlusion position in the pulmonary tree, where the balloon was deflated and the catheter secured. Measurements included arterial pressure (AP), central venous pressure (CVP), pulmonary arterial pressure (PAP), pulmonary artery occlusion pressure (PAOP), and cardiac output by thermo dilution technique (WTI, Wetenskappwlijk, Technische Instituut, the Netherlands). In one pig the PAOP was not measured. In one pig there were technical difficulties resulting in no cardiac output values. Mixed venous blood was obtained from the PA catheter. All pressures were measured using fluid filled catheters and pressure transducers (Ohmeda Inc., USA) at the midaxillary level. All pressure measurements as well as heart rate was registered using computer software (Acqknowledge, Biopac systems Inc., USA).

\section{Preparation and sampling}

From each animal $150 \mathrm{ml}$ blood was drawn in $50 \mathrm{ml}$ syringes containing $5 \mathrm{ml}$ sodium citrate buffer $(0.13 \mathrm{M})$. The blood was drawn directly after the arterial catheter was inserted and one liter of ringer's acetate was administrated, to compensate for the loss of blood volume while the rest of the instrumentation was completed. The animals were allowed a period of 1 hour in order to stabilize after the instrumentation. Heart rate, blood pressure (AP, PAP, CVP), temperature and blood gases were monitored and were stable before the experiment was started. The blood drawn from the pigs was filtrated through leukocyte removal filters (BioR 01 plus, Fresenius AG, Germany). To $10 \mathrm{ml}$ of this blood, 1-2 MBq of ${ }^{51} \mathrm{Cr}$ (NEZ-030, PerkinElmer, Boston, MA) was added and the blood was put in a $37^{\circ} \mathrm{C}$ water bath for 1 hour, followed by centrifugation $(3000 \mathrm{rpm})$ to separate blood cells from plasma. The blood cells were washed with $0.15 \mathrm{M}$ sodium chloride two times. Five $\mathrm{ml}$ of the radio labelled blood was injected back to the animal 15 minutes before the experiment started. The other $5 \mathrm{ml}$ was mixed with the remaining filtered blood and exposed to carbon monoxide $\left(5 \%\right.$ in $\left.\mathrm{N}_{2}\right)$ (AGA Gas, Sundbyberg, Sweden) for approximately 1.5 hours. This blood was analyzed for COHb (OSM3 hemoximeter, Radiometer, Denmark) before a known amount (mean $83 \mathrm{ml}$, range 70-90 ml) was injected back to the animal during a period of 2 minutes. The oxygen saturation curve of the OSM3 hemoximeter was modified for porcine hemoglobin. When all blood was administrated the experiment started. The amount 
of injected $\mathrm{COHb}$ was determined according to the weight of the animal, with the goal to achieve approximately 3 percent $\mathrm{COHb}$ in the animal directly after injection. A $\mathrm{COHb}$ value of $3 \%$ was chosen as a level significantly higher than the physiological $\mathrm{COHb}$ level of $0.5 \%$, whilst not being an intoxicating amount of $\mathrm{COHb}$.

Blood samples were drained in syringes and directly transferred to $1.8 \mathrm{ml}$ sodium citrate tubes (Vacutainer Becton Dickinson, USA) from both the arterial catheter as well as the PA catheter according to the protocol. The samples were stored at $+4{ }^{\circ} \mathrm{C}$ and analyzed the next day for carbon monoxide. Blood samples stored in a refrigerator are stable for several days, as described earlier by our laboratory (Sundin and Larsson, 2002). Blood samples for $\mathrm{Hb}$ and $\mathrm{COHb}$ analyses were drained from the arterial catheter and from the PA catheter and analyzed immediately using heme oximetry. Arterial and mixed venous blood was analyzed for $\mathrm{pH}, \mathrm{pCO}_{2}, \mathrm{pO}_{2}, \mathrm{SBC}$ and $\mathrm{BE}$ (ABL5 auto analyzer, Radiometer, Denmark). The exhaled air from the animals where collected in 101 gas bags under 45 seconds and was analyzed in triplicates immediately on a gas chromatograph with flame ionization detection (Sundin and Larsson, 2002). The radioactivity in blood was calculated as counts per minutes in a gamma counter (Wallac 1480 Wizard, Wallac, Finland).

\section{Experimental Protocol}

Measurements were collected just before injection of blood, then at intervals over 300 minutes. Five samples for carbon monoxide determination with 5 minutes interval were drained as baseline values before the injection was made. Arterial and mixed venous blood samples after carbon monoxide injection were collected at 3, 5, 10, 15 and 20 minutes, followed by every 10 minutes until 60 minutes, after which the sampling interval was 20 minutes. Samples were analyzed for carbon monoxide and radioactivity. Blood gases and heme oximetry measurements as well as cardiac output, temperature, $\mathrm{SpO}_{2}$ and exhaled air were obtained before the injection of blood and then after 10 and 20 minutes followed by a sampling interval of 20 minutes. Blood pressures and heart rate were recorded continuously during the whole protocol.

Analysis

\section{Carbon monoxide determination}

Samples in duplicate containing $400 \mu \mathrm{l}$ blood and a glass bead were put into gas tight containers. Reagent (saponin and sulphuric acid) was added and the gas phase injected and analyzed on a gas chromatograph with flame ionization detection fitted with a nickel catalyst as previously described from our lab (Sundin and Larsson, 2002).

\section{Pharmacokinetical calculations}

For kinetic calculations the carbon monoxide concentration in blood was plotted versus time using the pharmacokinetical software WinNonlin (Pharsight Corporation, Palo Alto, USA). The basal concentration $\left(\mathrm{C}_{\mathrm{B}}\right.$, mean of samples before injection) was first withdrawn from all values. The carbon monoxide (X) dose given to the animals was calculated using the following formula;

$$
\mathrm{X}=\mathrm{COHb} / 100 \cdot 4 / 64400 \cdot 10^{9} \cdot \mathrm{Hb} \cdot \mathrm{V}
$$


where $\mathrm{COHb}$ is the carboxyhemoglobin fraction in percent of the bubbled blood before injection, $\mathrm{Hb}$ is the hemoglobin concentration $\left(\mathrm{g} \cdot \mathrm{1}^{-1}\right)$ of the pig before injection, $\mathrm{V}$ is the injected volume (l) of the bubbled blood, 64400 is the molecular mass of hemoglobin, the constant 4 represents the four binding sites of hemoglobin to carbon monoxide.

Systemic vascular resistance index (SVRi) and pulmonary vascular resistance index (PVRi)

$$
\begin{aligned}
& \mathrm{SVRi}=(\text { MAP }-\mathrm{CVP}) /(\text { cardiac output } / \text { bsa }) \\
& \text { PVRi }=(\text { MPAP }-\mathrm{PCWP}) /(\text { cardiac output } / \text { bsa }) \\
& \text { bsa }=\text { body surface area of the pig, } 0.11 \cdot \text { bodyweigt }^{0.65}
\end{aligned}
$$

(Stahl, 1967)

MAP $=$ mean arterial pressure

MPAP $=$ mean pulmonary arterial pressure.

\section{Exhaled air}

Carbon monoxide analysis of the exhaled air was made using gas chromatography with flame ionization detection. The amount of exhaled carbon monoxide was calculated by integrating the differences between such analyses and the basal, exhaled carbon monoxide concentration over time. The eliminated fraction of the dose was calculated using the injected dose determined as described above.

\section{Results}

\section{Carbon monoxide analysis in blood}

The results from the analysis of carbon monoxide in blood are shown in Fig. 1. No difference in the concentration of carbon monoxide could be detected between arterial and mixed venous blood. At the end of the protocol, basal concentrations of carbon monoxide demonstrated that the protocol time returned to baseline pre exposure levels.

\section{Pharmacokinetics}

The elimination of carbon monoxide from blood followed first-order kinetics. Kinetic data for carbon monoxide in blood are shown in Table 1. Correlation of observed carbon monoxide values to the curve equation was high in all animals. There was a difference between the distribution volumes, as determined by the pharmacokinetical model and by ${ }^{51} \mathrm{Cr}$ calculations. The basal concentrations of carbon monoxide were similar in all animals. 


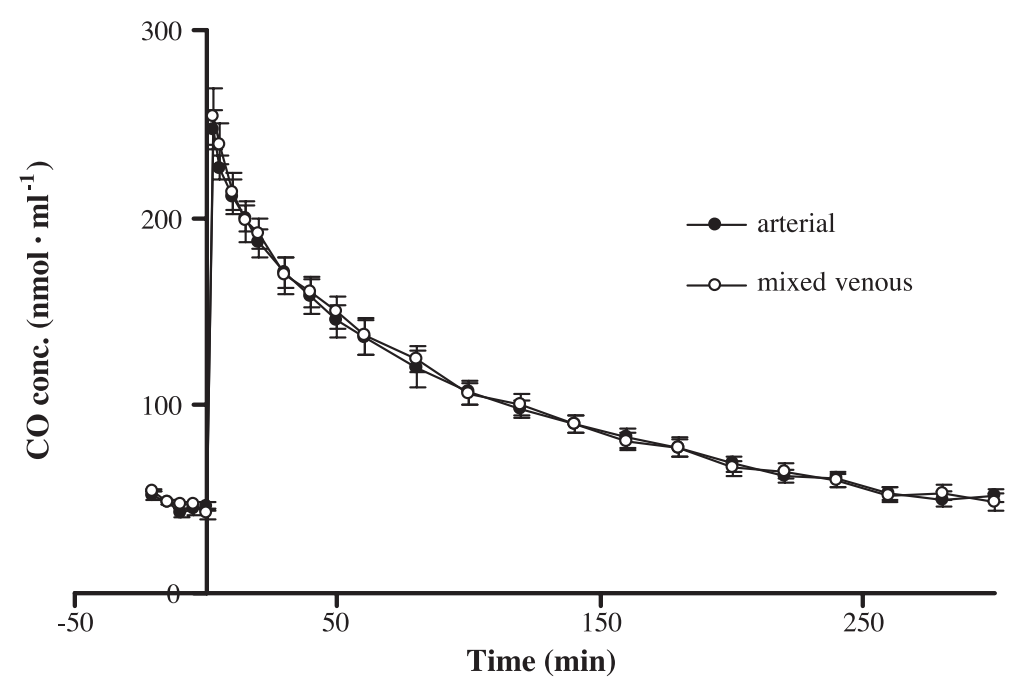

Fig. 1. Concentration of carbon monoxide (mean \pm SEM, $n=6$ ) in blood during the protocol. At time 0 , carbon monoxide saturated blood was injected intravenously.

\section{Exhaled air}

Results from the analysis of exhaled air are shown in Fig. 2. The eliminated fraction of the dose is plotted against time with standard error of mean (SEM). After 160 minutes the eliminated fraction of the dose is approximately $100 \%$, which shows that all exogenously administered carbon monoxide has been cleared.

\section{${ }^{51}$ Cr analysis}

To study the effect of carbon monoxide saturation on the kinetics of red blood cells, ${ }^{51} \mathrm{Cr}$ was incorporated in red blood cells and the decay in blood followed. First, a small bolus of control red blood

Table 1

Individual pharmacokinetic data in arterial blood from 6 pigs, injected with a known amount of carbon monoxide in blood

\begin{tabular}{|c|c|c|c|c|c|c|c|c|}
\hline & Pig 1 & Pig 2 & Pig 3 & Pig 4 & Pig 5 & Pig 6 & Mean & SEM \\
\hline Dose $(\mu \mathrm{mol}) \mathrm{X}$ & 302 & 402 & 388 & 433 & 382 & 455 & 393 & 21 \\
\hline $\mathrm{V}^{\mathrm{a}}(\mathrm{ml})$ & 1625 & 2065 & 1856 & 2434 & 2375 & 2266 & 2101 & 128 \\
\hline $\mathrm{K}_{10}$ & 0.017 & 0.010 & 0.011 & 0.009 & 0.012 & 0.012 & 0.012 & 0.0011 \\
\hline Correlation coefficient & 0.995 & 0.995 & 0.991 & 0.979 & 0.985 & 0.990 & & \\
\hline Half life (min) & 40.4 & 67.2 & 64.4 & 75.4 & 57.5 & 58.9 & 60.5 & 4.7 \\
\hline Clearance $\left(\mathrm{ml} \mathrm{min}^{-1}\right)$ & 27.8 & 21.3 & 20.0 & 22.4 & 28.6 & 26.7 & 24.5 & 1.5 \\
\hline Weight $(\mathrm{kg})$ & 24 & 29 & 28 & 28 & 29 & 30 & 28 & 0.9 \\
\hline $\mathrm{C}_{\mathrm{B}}^{\mathrm{b}}\left(\mathrm{nmol} \mathrm{ml} \mathrm{l}^{-1}\right)$ & 48.9 & 48.2 & 49.4 & 43.0 & 40.0 & 46.9 & 46.1 & 3.8 \\
\hline $\mathrm{V}^{\mathrm{c}}(\mathrm{ml})$ & 2186 & 1957 & 1696 & & 2193 & 1999 & 2006 & 10 \\
\hline
\end{tabular}

Equation of curve (Fig. 1): $\mathrm{C}(\mathrm{t})=\mathrm{C}_{B}+\mathrm{X} / \mathrm{V} \mathrm{e}^{\mathrm{k} 10 \mathrm{t}}$.

${ }^{a}$ Distribution volume as determined by carbon monoxide analysis.

${ }^{\mathrm{b}}$ Basal concentration of carbon monoxide.

${ }^{\mathrm{c}}$ Distribution volume as deternmined by ${ }^{51} \mathrm{Cr}$ analysis. 


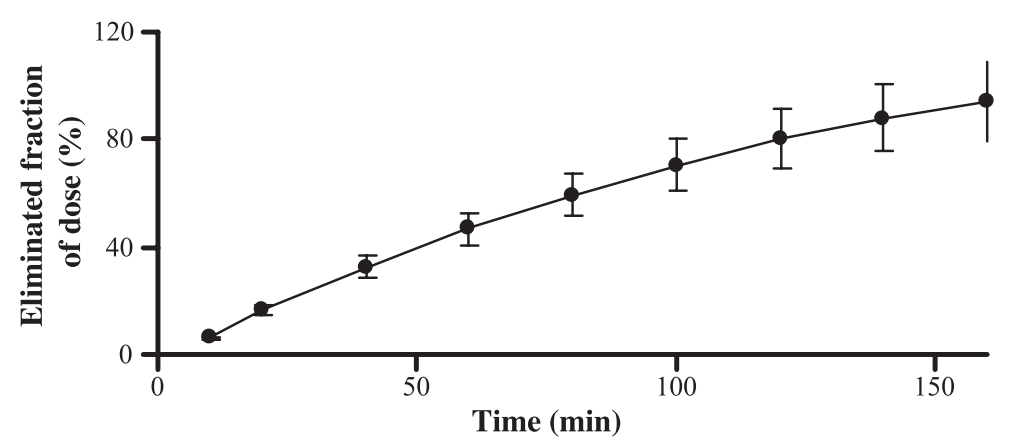

Fig. 2. Eliminated fraction of the carbon monoxide total dose, analyzed in exhaled air from animals which received carbon monoxide saturated blood, mean $\pm \operatorname{SEM}(n=6)$.

cells was given and then the carbon monoxide containing bolus of red blood cells. The apparent distribution volumes were $72 \pm 4.0 \mathrm{ml} \cdot \mathrm{kg}^{-1}$ for the first injectate and $72 \pm 3.3 \mathrm{ml} \cdot \mathrm{kg}^{-1}$ for the second injectate. There was no significant change in distribution volume, nor in decay, indicating that no major changes in red blood cell kinetics was induced by this step (see Fig. 3).

\section{Physiological data}

Physiological parameters were measured during the whole experiment. Results from six points in the protocol are shown in Table 2. Body temperature increased during the protocol for all animals. Otherwise, all other parameters remained unchanged following carbon monoxide exposure.

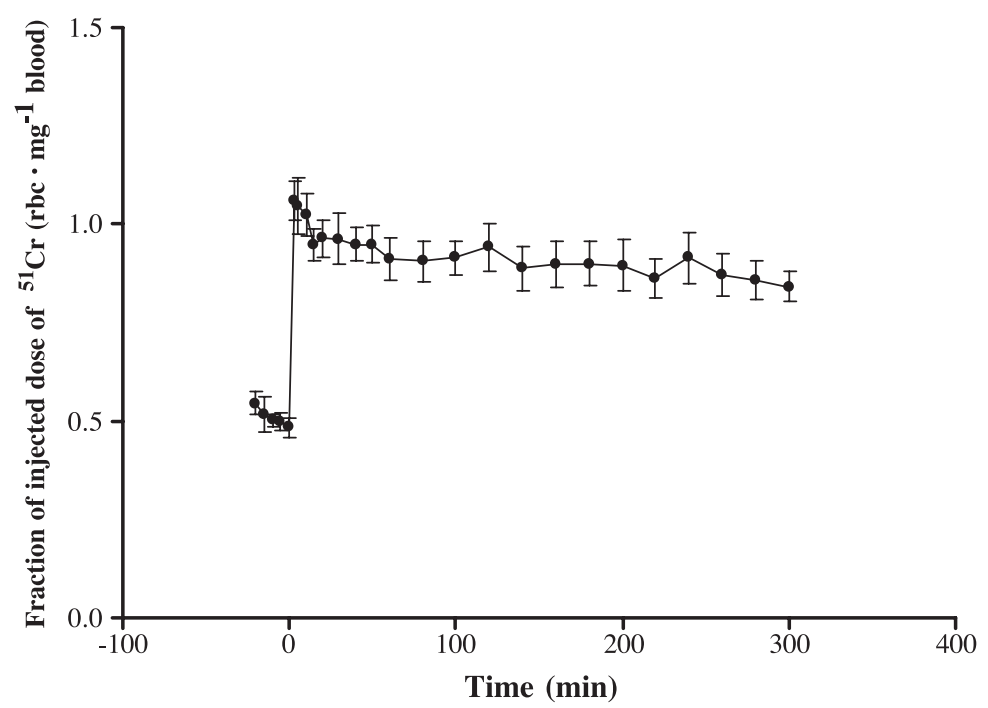

Fig. 3. Five $\mathrm{ml}^{51} \mathrm{Cr}$ labeled red blood cells (10-20 $\mu \mathrm{Ci}$ ) were injected intravenously to determine the blood volume. Then $70-90$ $\mathrm{ml}$ blood was infused with an $\mathrm{HbCO}$ content of 90-99 \% including $10-20 \mu \mathrm{Ci}^{51} \mathrm{Cr}$ in labeled red blood cells. Each individual received the same amount of radiolabel in the first and second bolus. 
Table 2

Physiological data recorded during the experiment with anesthetized pigs following the administration of carbon monoxide

\begin{tabular}{|c|c|c|c|c|c|c|c|c|c|c|c|c|}
\hline & \multicolumn{2}{|c|}{$\underline{\text { Before administration }}$} & \multicolumn{2}{|c|}{10 minutes } & \multicolumn{2}{|c|}{40 minutes } & \multicolumn{2}{|c|}{100 minutes } & \multicolumn{2}{|c|}{200 minutes } & \multicolumn{2}{|c|}{300 minutes } \\
\hline & Mean & SEM & Mean & SEM & Mean & SEM & Mean & SEM & Mean & SEM & Mean & $\overline{\text { SEM }}$ \\
\hline MAP (mmHg) & 105.8 & 4.2 & 108.0 & 4.4 & 109.2 & 4.1 & 96.7 & 3.4 & 93.5 & 4.7 & 92.0 & 4.9 \\
\hline MPAP (mmHg) & 18.8 & 2.6 & 21.0 & 2.8 & 20.4 & 2.4 & 16.8 & 1.7 & 17.0 & 1.6 & 18.2 & 1.8 \\
\hline CVP (mmHg) & 2.8 & 0.9 & 3.2 & 0.9 & 4.0 & 0.5 & 4.4 & 0.5 & 4.0 & 0.5 & 5.0 & 0.5 \\
\hline PCWP (mmHg) & 5.7 & 0.5 & 7.1 & 0.9 & 7.5 & 1.5 & 6.3 & 1.4 & 7.8 & 1.1 & 7.3 & 0.9 \\
\hline HR (bpm) & 111.8 & 8.9 & 112.7 & 7.3 & 112.5 & 7.1 & 107.9 & 5.8 & 108.9 & 7.2 & 107.5 & 7.9 \\
\hline Temp. $\left({ }^{\circ} \mathrm{C}\right)$ & 37.7 & 0.3 & 37.6 & 0.3 & 16.8 & 0.3 & 38.0 & 0.3 & 38.2 & 0.4 & 38.3 & 0.4 \\
\hline $\mathrm{SpO}_{2}(\%)$ & 99.0 & 0.3 & 98.8 & 0.3 & 98.3 & 0.3 & 98.2 & 0.4 & 97.5 & 0.8 & 97.8 & 0.5 \\
\hline $\begin{array}{l}\text { Card.Out. }\left(1 \cdot \mathrm{min}^{-1}\right) \\
(\mathrm{n}=5)\end{array}$ & 4.5 & 0.4 & 4.4 & 0.4 & 4.5 & 0.3 & 4.3 & 0.3 & 4.3 & 0.3 & 4.2 & 0.3 \\
\hline Vent. $\left(1 \cdot \min ^{-1}\right)$ & 6.8 & 0.4 & 6.8 & 0.4 & 6.8 & 0.4 & 6.8 & 0.4 & 6.8 & 0.4 & 6.7 & 0.4 \\
\hline $\mathrm{PH}$ & 7.49 & 0.01 & 7.49 & 0.01 & 7.48 & 0.01 & 7.51 & 0.01 & 7.50 & 0.01 & 7.48 & 0.01 \\
\hline $\mathrm{SBC}(\mathrm{mM})$ & 28.5 & 0.8 & 28.8 & 0.7 & 28.7 & 0.6 & 29.3 & 0.3 & 28.5 & 0.3 & 28.2 & 0.4 \\
\hline $\mathrm{BE}(\mathrm{mM})$ & 4.0 & 0.7 & 4.8 & 0.9 & 4.7 & 0.6 & 5.3 & 0.3 & 4.5 & 0.3 & 4.2 & 0.4 \\
\hline $\mathrm{PCO}_{2}(\mathrm{kPa})$ & 5.0 & 0.1 & 4.8 & 0.1 & 5.0 & 0.1 & 4.7 & 0.1 & 4.7 & 0.1 & 5.0 & 0.1 \\
\hline $\mathrm{PO}_{2}(\mathrm{kPa})$ & 18.5 & 1.2 & 18.7 & 0.9 & 18.4 & 0.7 & 17.9 & 1.1 & 16.9 & 1.1 & 15.7 & 0.8 \\
\hline Arterial $\mathrm{Hb}\left(\mathrm{g} \cdot \mathrm{l}^{-1}\right)$ & 80.1 & 2.4 & 81.7 & 3.2 & 81.8 & 2.2 & 80.2 & 2.3 & 75.4 & 2.9 & 75.3 & 2.8 \\
\hline
\end{tabular}

Mean \pm SEM, $n=6$ unless otherwise indicated.

\section{SVRi and PVRi}

In Fig. 4, SVRi and PVRi are plotted versus time after administration of carbon monoxide. There are no changes over time either in SVRi or in PVRi.

\section{SVRi}

$\left(\mathrm{mmHg} \cdot \min \cdot \mathrm{m}^{2} \cdot \mathrm{L}^{-1}\right)$

\section{PVRi}

$\left(\mathrm{mmHg} \cdot \mathrm{min} \cdot \mathrm{m}^{2} \cdot \mathrm{L}^{-1}\right)$

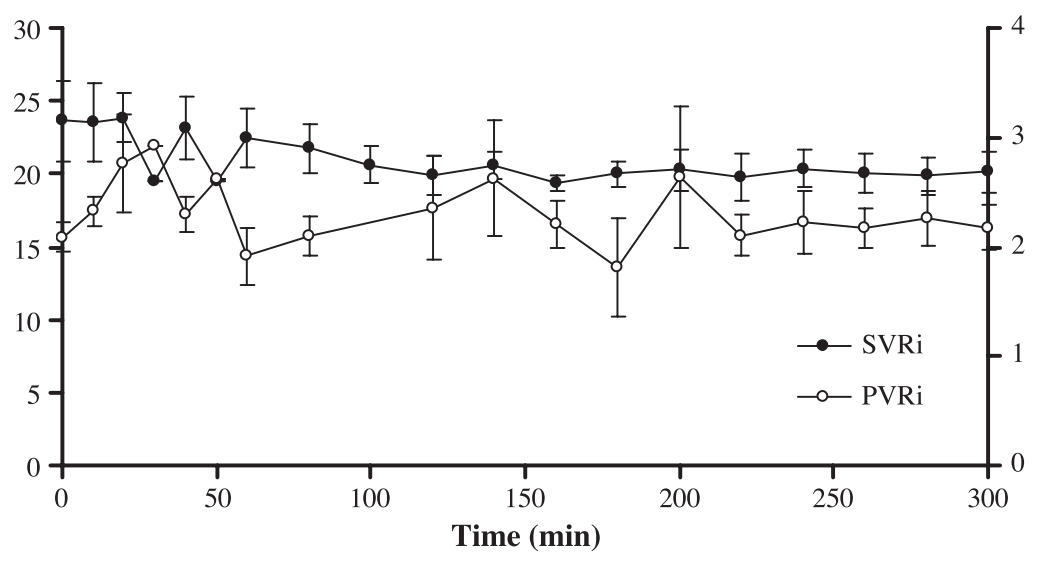

Fig. 4. Systemic vascular resistance index $(n=5)$ and pulmonary vascular resistance index $(n=4)$ versus time in pigs after administration of carbon monoxide (time 0 ). 


\section{Discussion}

In the present study no changes in pulmonary vascular resistance were observed after acute i.v. administration of carbon monoxide. Previous in vitro findings have shown a decrease in vascular resistance after addition of carbon monoxide (Suematsu et al., 1995). Other studies also indicate that carbon monoxide can have a vasodilatory effect during specific conditions (Bauer et al., 1996; Motterlini et al., 1998; Horváth et al., 1998; Yet et al., 1997). However, a study on late-gestation fetal lambs under normal conditions showed that inhaled carbon monoxide did not cause pulmonary vasodilatation, and the inhibition of HO did not cause any circulatory changes (Grover et al., 2000). Another study reported no changes in pulmonary circulation in dogs during hypoxemia after inhalation of carbon monoxide or after HO inhibition (Vassalli et al., 2001). A third study showed a small decrease in PVR in sheep during hypoxemia after inhalation of carbon monoxide (Nachar et al., 2001). Thus, in vivo studies have demonstrated dissimilar effects of carbon monoxide on vascular resistance. The explanation for these different previous results is not clear. Possibly, differences in tissue oxygenation or the degree of stress response could influence the circulatory effect. The effect may be local and involve free carbon monoxide. Significant carbon monoxide binding to hemoglobin may reduce such effects. The free carbon monoxide concentration is also increased when carbon monoxide is administered as $\mathrm{COHb}$, but the local concentration may still be too small.

The frequently used method of calculating vascular resistance using blood pressure and blood flow may also not be sensible enough to detect a vasodilatory response following carbon monoxide exposure. Homeostatic mechanisms could counteract carbon monoxide-induced vasodilatation in different vascular beds. This could occur in a mode resulting in no net effect on the systemic vascular resistance index (SVRi), if we have a situation with mixed and opposite effects in different organs. However, if vasodilatation would be the result of carbon monoxide on the pulmonary circulation, a result on the pulmonary vascular resistance index (PVRi) has to occur, since this is a single-organ measure based both on pulmonary artery pressure and pulmonary artery blood flow. We feel that these measures are sensitive enough to detect a vasodilatation of circulatory importance.

The interactions between carbon monoxide and nitric oxide are not fully understood and may play an important role in regulating the circulation. One possible interaction may be that if carbon monoxide is administrated, less nitric oxide is produced, resulting in the same net effect on the circulation. The same occurs when less carbon monoxide is available locally, that more nitric oxide may be produced and circulatory homeostasis is maintained. The effect of carbon monoxide on guanylate cyclase is much less potent than nitric oxide (Wang, 1998). One hypothesis is that while nitric oxide has an effective binding to cGMP, the essential role for carbon monoxide is to influence the P-450 system (Coceani et al., 1996).

One way to inhibit HO is by the use of metalloporphyrines. One study concludes that metalloporphyrines should not be used because they also inhibit sGC and changes nitric oxide synthase activity (Grundemar and Ny, 1997). This can be an explanation for studies where no effects after inhibition of $\mathrm{HO}$ are detected.

Before discounting carbon monoxide as a vasodilator, more in vivo studies, need to be done since several studies in vitro show that it has a circulatory effect (Wang, 1998). Investigations regarding where and when carbon monoxide is produced would be relevant. Techniques like microdialysis could be helpful in such studies.

We were concerned that our method to bubble erythrocytes with carbon monoxide for $11 / 2$ hour would change the kinetics of the red blood cells. To investigate this, we used ${ }^{51} \mathrm{Cr}$ to radiolabel red blood 
cells. Labeled red blood cells were given twice. First, a small bolus that had only been radio labeled and then labeled red blood cells that had been saturated with CO. There were no major differences in distribution volumes or in half-life, indicating that that the carbon monoxide saturated red blood cells at least were not severely damaged by the procedure.

Carbon monoxide is produced continuously in the body, resulting in elimination that may follow first order kinetics. Previous studies have shown second order or multi-compartmental pharmacokinetics for carbon monoxide (Shimazu et al., 2000; Wagner et al., 1975; Wazawa et al., 1996). The differences in protocols of different studies may influence the modeling of carbon monoxide concentrations. As discussed previously (Shimazu, 2001), a distribution phase may be observed initially following intoxicating exposure to carbon monoxide, resulting in a biphasic concentration decrease. This probably occurs when there is significant distribution to tissues. In the present study, the half-life of carbon monoxide was 60.5 minutes, which is different compared with other studies. These different half-lives during the elimination phase in different studies are difficult to understand. One explanation could be physiological differences, such as differences in ventilation and cardiac output. Different types of administration may be another explanation for these differences, since an equilibrium process between the alveolar gas and blood is involved when patients are exposed to carbon monoxide via the lung. This equilibration process is not present in our experiment, in which carbon monoxide is administered directly into the blood. However, another mechanism could be different durations of carbon monoxide exposure, i.e. differences in dose (Shimazu, 2001). The possibility of such dose-dependent elimination, Michaelis-Menten kinetics, can not be excluded for carbon monoxide.

The present study shows that $100 \%$ of the administered carbon monoxide was recovered in exhaled air after 160 minutes (Fig. 2). Thus, the lung seems to be the only organ responsible for elimination. No differences between mixed venous blood and arterial blood were detected, and the elimination breath-tobreath is very small. It is likely that the mode of ventilation will influence the rate of elimination of carbon monoxide, and in this study, the ventilation was controlled mechanically, resulting in less variability due to this factor.

In conclusion, this experiment shows that an exact and low dose of carbon monoxide inducing concentrations that would be expected during physiological conditions in pigs, does not result in significant circulatory effects. No other study has studied carbon monoxide pharmacokinetics at physiological concentrations.

\section{Conclusion}

We conclude that carbon monoxide acutely administrated at physiological doses does not bring about significant circulatory effects. Also, elimination of carbon monoxide administrated in this dose range follows first order kinetics. This information can be of value in designing further studies to investigate carbon monoxide's effects on the circulation.

\section{Acknowledgements}

Financial support from the Medical Faculty, University of Umeå is gratefully acknowledged. 


\section{References}

Bauer, M., Pannen, B.H.J., Bauer, I., Herzog, C., Wanner, G.A., Hanselmann, R., Zhang, J.X., Clemens, M.G., Larsen, R., 1996. Evidence for a functional link between stress response and vascular control in hepatic portal circulation. American Journal of Physiology 271 (5 pt 1), 929-935.

Coceani, F., Kelsey, L., Seidlitz, E., 1996. Carbon monoxide-induced relaxation of the ductus arteriosus in the lamb: evidence against the prime role of guanylyl cyclase. British Journal of Pharmacology 118 (7), 1689-1696.

Durante, W., Peyton, K.J., Schafer, A.I., 1999. Platelet-derived growth factor stimulates heme oxygenase-1 gene expression and carbon monoxide production in vascular smooth cells. Arteriosclerosis, Thrombosis, and Vascular Biology 19 (11), 2666-2672.

Grover, T.R., Rairigh, R.L., Zenge, J.P., Abman, S.H., Kinsella, J.P., 2000. Inhaled carbon monoxide does not cause pulmonary vasodilation in the late-gestation fetal lamb. American Journal of Physiology. Lung Cellular and Molecular Physiology 278 (4), 779-784.

Grundemar, L., Ny, L., 1997. Pitfalls using metalloporphyrins in carbon monoxide research. Trends in Pharmacological Sciences 18 (6), 193-195.

Horváth, I., Donnelly, L.E., Kiss, A., Paredi, P., Kharitonov, S.A., Barnes, P.J., 1998. Raised levels of exhaled carbon monoxide are associated with an increased expression of heme oxygenase-1 in airway macrophages in asthma: a new marker of oxidative stress. Thorax 53 (8), 668-672.

Kreck, T.C., Shade, E.D., Lamm, W.J.E., McKinney, S.E., Hlastala, M.P., 2001. Isocapnic hyperventilation increases carbon monoxide elimination and oxygen delivery. American Journal of Respiratory and Critical Care Medicine 163 (2), $458-462$.

Motterlini, R., Gonzales, A., Foresti, R., Clark, J.E., Green, C.J., Winslow, R.M., 1998. Heme oxygenase-1-derived carbon monoxide contributes to the suppression of acute hypertensive responses in vivo. Circulation Research 83 (5), $568-577$.

Nachar, R.A., Pastene, C.M., Herrera, E.A., Riquelme, R.A., Sanhueza, E.M., Troncoso, S., Llanos, A.J., 2001. Low-dose inhaled carbon monoxide reduces pulmonary vascular resistance during acute hypoxemia in adult sheep. High Altitude Medicine and Biology 2 (3), 377-385.

Pannen, B.H.J., Bauer, M., 1998. Differential regulation of hepatic arterial and portal venous vascular resistance by nitric oxide and carbon monoxide in rats. Life Sciences 62 (22), 2025-2033.

Sasaki, T., 1975. On half-clearance time of carbon monoxide hemoglobin in blood during hyperbaric oxygen therapy. Bulletin of Tokyo medical and dental university 22 (1), 63-77.

Shimazu, T., Ikeuchi, H., Sugimoto, H., Goodwin, C.W., Mason, A.D., Pruitt, B.A., 2000. Half-life of blood carboxyhemoglobin after short-term and long-term exposure to carbon monoxide. The Journal of Trauma 49, 126-131.

Shimazu, T., 2001. Half-life of blood carboxyhemoglobin. Chest 119, 661-663.

Siow, R.C.M., Sato, H., Mann, G.E., 1999. Heme oxygenase-carbon monoxide signalling pathway in atherosclerosis: antiatherogenic actions of bilirubin and carbon monoxide. Cardiovascular Research 41, 385-394.

Stahl, W.R., 1967. Scaling of respiratory variables in mammals. Journal of Applied Physiology 22 (3), $453-460$.

Suematsu, M., Goda, N., Sano, T., Kashiwagi, S., Egawa, T., Shinoda, Y., Ishimura, Y., 1995. Carbon monoxide: An endogenous modulator of sinusoidal tone in the perfused rat liver. Journal of Clinical Investigations 96 (5), 2431 -2437.

Sundin, A.M., Larsson, J.E., 2002. Rapid and sensitive method for the analysis of carbon monoxide in blood using gas chromatography with flame ionisation detection. Journal of Chromatography B 766 (1), 115-121.

Vassalli, F., Pierre, S., Julien, V., Bouckaert, Y., Brimioulle, S., Naeije, R., 2001. Inhibition of hypoxic pulmonary vasoconstriction by carbon monoxide in dogs. Critical Care Medicine 29 (2), 359-366.

Wagner, J.A., Horvath, S.M., Dahms, T.E., 1975. Carbon monoxide elimination. Respiration Physiology $23,41-47$.

Wang, R., 1998. Resurgence of carbon monoxide: an endogenous gaseous vasorelaxing factor. Canadian Journal of Physiology and Pharmacology 76 (1), 1-15.

Wazawa, H., Yamamoto, K., Yamamoto, Y., Matsumoto, H., Fukui, Y., 1996. Elimination of CO from the body: an experimental study on the rabbit. Nippon Hoigaku Zasshi 50 (4), 258-262.

Weaver, L.K., Howe, S., Hopkins, R., Chan, K.J., 2000. Carboxyhemoglobin half-life in carbon monoxide-poisoned patients treated with $100 \%$ oxygen at atmospheric pressure. Chest 117 (3), 801-808.

Yet, S.F., Pellacani, A., Patterson, C., Tan, L., Folta, S.C., Foster, L., Lee, W.S., Hsieh, C.M., Perrella, M.A., 1997. Induction of heme oxygenase-1 expression in vascular smooth muscle cells. The Journal of Biological Chemistry 272 (7), $4295-4301$. 